\title{
Possibility of Sustainable Development of Genki Forest and Investment Decision Based on POCD Framework
}

\author{
Liying Liu ${ }^{1, * a, \dagger}$, Junyao $\mathrm{Mu}^{2, *, b, \dagger}$, Zishi Wang ${ }^{3, *, c, \uparrow}$ \\ ${ }^{1}$ School of Finance, Capital University of Economics and Business, Beijing, 100070, China \\ ${ }^{2}$ Sauder School of Business, University of British Columbia, Vancouver, V6T 1Z4, Canada \\ ${ }^{3}$ School of Ecnomics, Capital University of Economics and Business, Beijing, 100070, China \\ *Corresponding author.Email: ${ }^{a}$ carolliu_0919@outlook.com; ${ }^{b}$ ericmu@student.ubc.ca $;{ }^{\cdot}$ wangzishi@cueb.edu.cn \\ These authors contributed equally.
}

\begin{abstract}
Genki Forest is a trending Chinese beverage company that is focusing on sugar-free drinks such as soda pops and milk tea. Before investing in Genki Forest, a venture capitalist should carefully analyze the company. However, the traditional methods, including the debt-to-equity ratio, the valuation on cash flow, and the cost are not suitable for Genki Forest compared to the POCD Framework, which covers People, Opportunity, Context and Deal, since none of them can fully reflect other aspects besides the financial status. This study contains a detailed examination of the founder of Genki Forest, the opportunity it has in the Chinese beverage market, and the overall social context that might influence Genki Forest's operation. Although there are some challenges that Genki Forest might face, such as low barriers to entry, and the unavoidable competition with the traditional beverage giants, the overall operating condition is still advantageous due to the rapid expansion of the Chinese beverage market. Therefore, after conducting this study, a venture capitalist should be confident about Genki Forest's potential, and other beverage enterprises should consider studying or applying the same strategies from Genki Forest.
\end{abstract}

Keywords: Genki Forest, Venture Capital, POCD Framework, Chinese Beverage Market, Start-up Company.

\section{INTRODUCTION}

China has one of the largest soft drink markets in the world. According to a Frost \& Sullivan report, China's soft drinks market is 991.4 billion yuan in 2019 in terms of retail sales, growing at a compound annual growth rate of $5.9 \%$ from 2014 to 2019. and it will continue to grow with the same compound annual growth rate from 2019 to 2024 [1]. A market-oriented approach to innovation emphasizes the need for firms to engage with the consumer in a systematic multinational approach to product development.

Daily soft drink consumption significantly increases the risk of moderate-to-severe acne in adolescents, especially when the sugar intake from any type of soft drink exceeds $100 \mathrm{~g}$ per day [2]. Health is a very hot topic in China, and the percentage of overweight Chinese people, especially small children, is gradually increasing. The overweight and obesity prevalence increased from $17.1 \%$ in 2010 to $22.5 \%$ in 2014 [3].With the capacity to meet consumer expectations for convenience and indulgence without unwanted kilojoules, drinks containing non-nutritive sweeteners enable the small change in health behavior that individuals are willing to consider [4]. Caloric menu labeling is currently used as a strategy to promote healthier dietary choices [5]. Although there are concerns that sugar substitutes can be harmful to the body, studies have proven that there is no risk [6]. In this context, many companies have emerged that need financing and it is important for investors to determine whether these companies have growth potential. Genki Forest is one such example.

Due to the advantages of the market, Genki Forest is growing rapidly [7]. In March 2021, Genki Forest announced the completion of a new round of strategic financing, with a post-investment valuation of US\$6 billion. This is the sixth round of financing and the second round of strategic financing of Genki Forest since its angel round in 2018. In this round of financing, new shareholders Warburg Pincus, L Catterton, and Temasek appeared, as well as old shareholders Sequoia China, Gaorong Capital, and every Capital. Among them, Warburg Pincus is the largest new investor. The rapid 
progress of financing means that the valuation of Genki Forest has risen by about three times in less than a year.

We try to analyze why Genki Forest received so many investments and determine if Genki Forest is worth investing in in the future. Generally, the traditional valuation methods for firms (cost approach, income approach, and market approach) do not work for startups. The main issue that limits the use of traditional valuation methods is the absence of typical information they need to work correctly. There is no data on past revenue or cash flow (the company is newly started), often there are not market data (absence of comparable firms/transactions), companies' assets are intangible and difficult to evaluate objectively [8].

The advantage of the POCD framework is that it does not require a large amount of data about the company's finances and considers various factors related to the company, allowing a more comprehensive judgment of whether the company has the potential for sustainable development and whether to invest in the company. There is a lack of research on the application of the POCD model to the analysis of Genki Forests.

\section{METHODOLOGY}

By using the POCD framework, the investors are required to analyze the company in terms of People, Opportunity, Context, and Deal. In the people category, "individuals or groups who perform services or provide resources" for the company should be analyzed [9]. These people might not be employed by the venture, but they are essential stakeholders that are strongly related to the development of the company. In terms of the opportunity category, it includes "any activity requiring the investment of scarce resources in hopes of future return". In comparison, the Context category includes factors that "affect the outcome of the opportunity but that are generally outside the direct control of management". Lastly, the Deal category refers to "the complete set of implicit and explicit contractual relationships between the entity and all resource providers". For startups, the Deal category is not needed to be considered in the POCD analysis [9].

In this paper, we will take Genki Forest as an example to show how the POCD framework is used in analyzing whether a startup worth to be invested. In the people section, we analyzed Mr. Tang Binsen, founder of Genki Forest. In the opportunity section, we analyzed the characteristics and prospects of the Chinese beverage market and compared Genki Forest with other major competitors. In the context section, we analyzed the impact of new retail channels, consumers, policies on Genki Forest's development, and the company's internal issues.

\section{THE PROCESS OF POCD FRAMEWORK ANALYSIS OF GENKI FOREST}

In this section, we will analyze Genki Forest by using the POCD framework, including People, Opportunity, and Context, respectively.

\subsection{People}

The founder, Mr. Tang Binsen, is an unconventional player in the beverage industry. Mr. Tang was born in Anhui China in 1982. After graduating from Beihang University, he founded Beijing ELEX Technology Co., Ltd in 2008. ELEX was a famous social network platform and a huge video game company at that time. With the success of the game: Happy Farm, Mr. Tang was able to earn his first pod of gold by selling ELEX for 2.6 billion Yuan in 2014. Mr. Tang is a firm believer in innovation and his experience of founding an internet company has provided him with a novel business strategy that the traditional beverage giants do not have, which is the celebrity economy. Celebrity economy is a marketing strategy defined as having frequent collaborations with internet celebrities through lives and social platforms to build a reputation of fashion, trendy for their product to attract young customers. In that case, teenagers are willing to spend their time and money on trendy products, despite the actual quality because they are irrational. Even though Mr. Tang has no experience in managing a manufacturing company and he might pay too much attention to marketing and neglect the quality of the products. He understands the logic of their young customers very well. By applying this novel strategy in the beverage market, Genki Forest is able to attract new customers quickly. Also, Mr. Tang's previous experience of managing a large company demonstrates his ability to lead Genki Forest to a higher level.

\subsection{Opportunity}

\subsubsection{Competition}

The biggest problem that Genki Forest is facing is that the barrier of the sugar-free soda industry is too low, producing many imitations of Genki Forest in the market.

We compared Genki Forest with its competitors. In terms of packaging, Hey Tea and Genki Forest's products are very similar, Coca-Cola AHHA from the Coca-Cola and soda from Nongfu spring are uniquely packaged. In terms of price, the prices are concentrated in 3 to 5, with Nongfu spring's soda and Coca-Cola's AHHA are cheaper. In terms of flavor, they are focused on peach, lemon, grape, and orange. Genki Forest's soda has significantly more flavors than the others. In terms of product launch time, Genki Forest's soda started selling in 2018 and was the earliest sugar-free soda to enter the 
market, with other products entering the market for a shorter period.

In conclusion, Genki Forest is the precursor of applying celebrity economic in the industry, it has gained brand awareness, customer loyalty, and market data, online sales far exceed other brands' products and creating a sustainable competitive advantage within the industry.

However, due to the low barriers to entry, many brands have also started to develop sugar-free soda, Hey Tea has a good reputation in the hearts of young people, the brands of Coca-Cola and Nongfu Spring are influential and deeply rooted, and have mature R\&D teams, production equipment, and sales channels, with product prices lower than Genki Forest's sugar-free soda. Thus, for Genki Forest, although it is currently the company with the largest market share, it faces a huge challenge.

\subsubsection{Reputation}

For a company like Genki Forest, which is constantly releasing new products, reputation is very important. A good reputation can help their new products have a good sale. Currently, many young consumers love Genki Forest due to the popularity of sugar-free soda.

Recently Genki Forest has encountered trouble, their milk teas are not zero sugar, although they claim to be zero cane sugar, and consumers feel they have received deception. The incident of Genki Forest defrauding consumers caused a discussion online and negatively impacted the company's reputation. Eventually, Genki Forest issued an apology on Weibo and compensated consumers with money.

In addition, there was an incident in which the packaging of Genki Forest products imitated Japanese beverages by using similar colors, composition and some Japanese elements to fake their products as Japanese products, which caused consumer dissatisfaction, and Genki Forest eventually updated the packaging of its products and removed the Japanese elements.

The zero-sugar incident and the packaging incident caused dissatisfaction among some consumers and had a negative impact on its reputation. In terms of aftercare, Genki Forest handled the case quickly and sincerely. As Genki Forest's sales gradually increase and consumers gradually become more numerous, similar incidents may occur again. Genki Forest can avoid accidents as much as possible and actively solve the problems as they have already had the experience.

\subsubsection{Market}

China has one of the largest soft drink markets in the world. According to a Frost \& Sullivan report, China's soft drinks market is 991.4 billion yuan in 2019 in terms of retail sales, growing at a compound annual growth rate of $5.9 \%$ from 2014 to 2019. and it will continue to grow with the same compound annual growth rate from 2019 to 2024 .

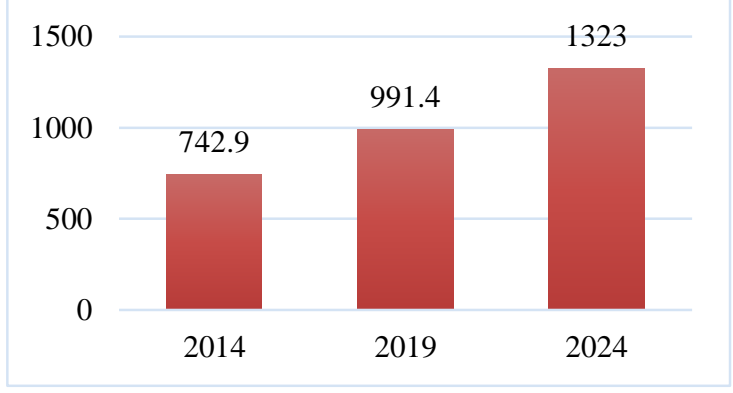

Figure 1 Market size of the Chinese soft drink industry.

Source: Filing Detail of Nongfu Spring Co., Ltd [1]

In terms of industry concentration, the market for the soft drinks industry is highly fragmented and the five largest players accounting for only $31 \%$ of the market share, which indicates that Genki Forest has the potential to become a major player in the industry.

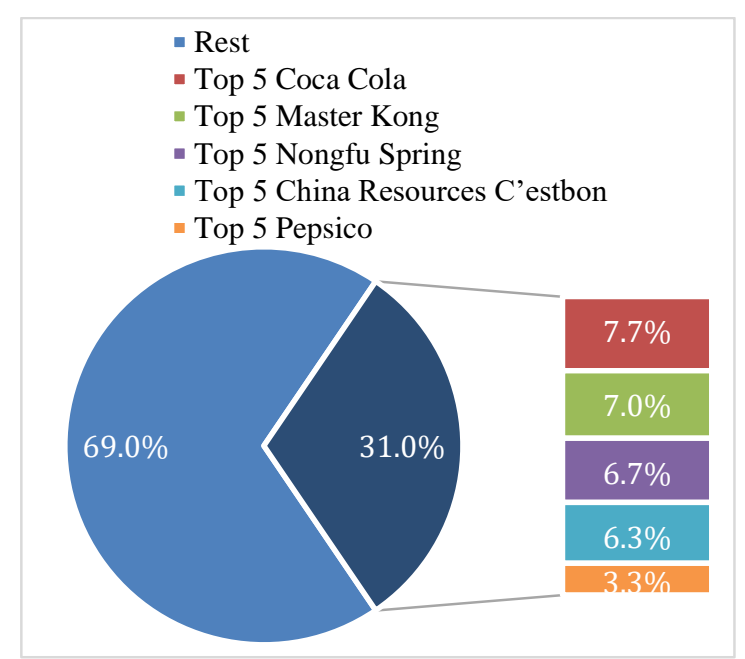

Figure 2 Industry competitive Landscape (2019 retail value).

Source: Filing Detail of Nongfu Spring Co., Ltd [1]

In terms of the channels of distribution, according to Frost \& Sullivan's report, the share of e-commerce channels will increase while the share of traditional channels will decrease by 2024 , which is beneficial for Genki Forest since it already has a huge influence on online selling platforms. 


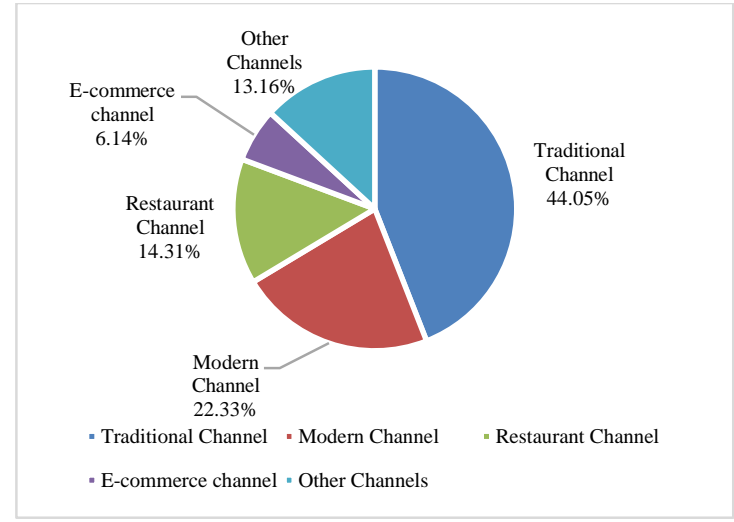

Figure 3 Percentage of consumption channels in China's soft drink market in 2019.

\section{Source: Filing Detail of Nongfu Spring Co., Ltd [1]}

In addition, the main consumer population is becoming concentrated in the youth population, with more than half of consumers aged between 20-29 years old, and $20.1 \%$ of people under 19 years old, indicating the substantial growth of Genki Forest's current customer segment.

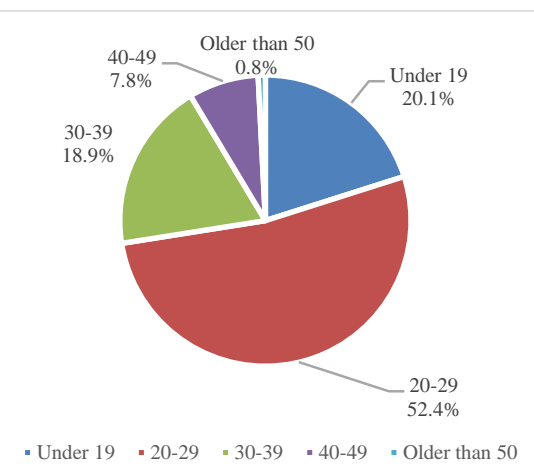

Figure 4 Age of consumers in China's soft drink market.

Source: Filing Detail of Nongfu Spring Co., Ltd [1]

An additional point is that although the current beverage consumers are predominantly $\mathrm{Z}$ generation and Genki Forest targets the same segment of the population, more types of consumers are a must if Genki Forest wants to have more lift. For people who are not Z Generation, some of the current strategies of Genki Forest, such as using only Tik Tok and other online channels for promotion and selling products mainly in the affluent areas of southeastern China, are limiting. So, in the future, Genki Forest needs to change its strategy to gain more consumers and a larger market share.

\subsection{Context}

\subsubsection{Consumption upgrade}

One might feel very optimistic in terms of the Context category of Genki Forest. The timing of entering the
Chinese beverage market provides huge potential for the company to grow. In recent years, the trend of consumption upgrade, quality revolution, strong brand recognition, and rise of new national brands was led by the increase in the Chinese new middle class. In these years, besides Genki Forest, a number of Chinese localized consumer brands were born, such as Perfect Diary, Hua Xizi, Xi Cha, and Nai Xue's Tea. These local brands challenge the traditional multinational giants in various fields such as beverages, cosmetics, new energy vehicles, and coffee, redefining categories by new technology, new consumption, and new quality. An important factor behind this is the rapid development of the Chinese economy, which has also led to the general trend of upgrading the consumption level and quality of Chinese consumer groups. Since the Chinese people have a stronger awareness and self-confidence in their local brands, this trend provides the greatest "fortune" for the rise of local beverage brands such as Genki Forest [10].

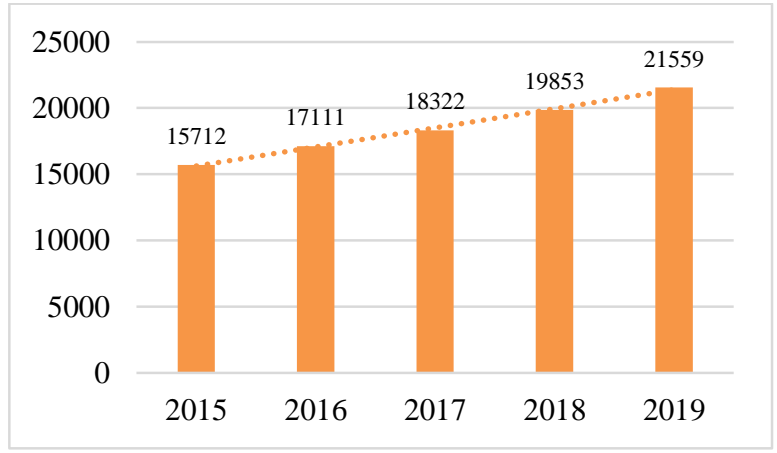

Figure 5 Statistics on Per Capita Consumption Expenditure of Chinese Residents from 2015 to 2019.

Source: Report.iimedia.cn.[11]

\subsubsection{E-commerce influence}

In addition, the rapid development of the Chinese ecommerce economy has provided a platform for the promotion and marketing of new national brands such as Genki Forest. Currently, the three e-commerce platforms, Tmall, Jingdong, and Pinduoduo are fully open to support new brands and become the focus of competition among the three major e-commerce platforms in the future [12]. Since 2016, Tmall has launched TMIC Innovation Center, Tmall Little Black Box, Super Category Day, and other marketing tools to promote the growth of new brands. In 2020, Tmall upgraded the "Tmall Super Rookie Program" to provide traffic, data, marketing, and other support for the development of new brands. Tmall's "Gather New Products" program helps 10,000 new national brands to develop new customers and new markets. In 2019, Jingdong also released the "Jingdong Super New Plan", launched the new product debut platform "Jingdong Little Magic Square", and created a whole lifecycle solution of "grass-planting - grass-pulling - grass-raising" for new products. The e-commerce 
platform has gradually become a fertile ground for the development of new brands, achieving the prosperity of new national brands and setting new records of "defeating big brands". In 2019, Tmall 618 sales data shows that Genki Forest sold 2.26 million bottles of drinks, taking the TOP1 in the beverage category; and double Eleven sales data shows that Genki Forest is the second largest in the network, beating Coca-Cola and Pepsi [13].

\subsubsection{Policy support}

Moreover, the local government also brought a customized "service package" policy to support Genki Forest at the location of its production base. This measure is designed to support key enterprises like Genki Forest in the process of future implementation regularly. It will bring comprehensive and multi-faceted assistance to Genki Forest in terms of government services, financial support, and talent construction [14]. Besides, in 2017, The government determined the national strategy of "Healthy China" and encouraged the whole society to reduce salt, oil, and sugar [15]. Due to the national policy advocacy for a healthy diet, the increasing disposable income of Chinese residents, the enhanced health awareness of residents, and the gradual improvement of consumers' acceptance of sugar-free drinks, it will definitely promote Genki Forest to layout sugar-free beverage racetracks and accelerate the research and development of sugar-free products, indicating a bright prospect of the company. In that case, the overall content is very beneficial to Genki Forest and its potential investors.

\subsubsection{Sinking market promotion blocked}

However, Genki Forest also has disadvantages in development. In the more price-sensitive downline market, Genki Forest does not have an advantage. In the FMCG industry, the role of the market and channels is very critical. But because Genki Forest has been mainly urban channels, it will miss a large number of sink markets [16]. Since entering the market, Genki Forest's target consumer group is the young consumers in first and second-tier cities. Convenience store chains that are favored by young people and have Internet genes which are the preferred channels for Genki Forest, such as 711, Family Mart, Boxing, and Convenience Bee. According to 711 's statistics, $88 \%$ of convenience store consumers are between the ages of 20 and 40, which is highly compatible with the user base of new consumer brands like Genki Forest. In Beijing, 711 has more of an advantage, opening close to 300 stores in total; Family has an overwhelming advantage in Shanghai, opening over 2,000 stores, and Rosen is also above 1,000 stores [17]. This suggests that once at the counter of a convenience store chain, the new brand will gain an excellent offline promotion position. However, to expand the company to a larger scale, it is far from enough to rely on the spread of first- and second-tier cities alone. The law of the beverage industry is that in size, it must be oriented to larger markets. In the second half of 2020 , Genki Forest's channel began to layout promotions to third and fourth-tier markets, and the first own production base was established. However, in the sinking market, it is much more difficult for Genki Forest to be recognized by consumers than in the cities. Zong Hao, founder and vice president of Genki Forest, once said, "Young people (buy drinks) in convenience stores do not look at the price, only choose the products they want and like the most, pick them up and go to the checkout." But in the sinking market, mainly in third and fourth-tier cities, the limits of consumption levels make this logic no longer apply. At present, the mainstream sugar-free sparkling water retail unit price is still 5 to 7 yuan, or even higher. In the sunken market with a large scale, such a price point does not sell well. If Genki Forest wants to open the sink market, it needs to further develop distribution channels in third and fourth line or even lower line cities, which is the most difficult to be shaken by the traditional beverage giants such as unity, Master Kong, Wahaha, Nongfu Mountain Spring [18].

\subsubsection{Insufficient ability to create popular products}

The present study confirmed the finding that in the Chinese beverage market, consumers like new very much and are tired of old [19]. Therefore, in such a market environment, Genki Forest must have the ability to continue product innovation. In the face of such a market, Genki Forest should have the ability to continuously innovate its products. Otherwise, it will be abandoned by consumers or overtaken by similar products with only one product. Now, in addition to the hottest tea drink "Burning Tea" and sparkling water, Genki Forest has been entering the market of tea drinks. In addition to the hottest tea drink, "Burning Tea" and sparkling water, Genki Forest has entered popular categories such as yogurt, milk tea, energy drinks, etc., but the market response is not as expected. In 2020, the sales of Genki forest will reach nearly 2.9 billion yuan, of which sugarfree bubble water will contribute about $70 \%$ (2.03 billion yuan), and the rest will mainly come from the sales of "Burning tea". In the official Taobao online store of Genki Forest, we can see that the sales of the new milk tea (low-fat) are far less than that of sparkling water, and the newly developed "Alien" functional drink has not caused an earthquake in the industry as before. From its launch of more than a dozen lukewarm products, Genki Forest cannot consistently create explosive models. In the face of such a market, Genki Forest must continue to refine. 
Table 1. The proportion and sales of diet drinks of some companies.

\begin{tabular}{|c|c|c|c|c|}
\hline Products & $\begin{array}{l}\text { The name of the } \\
\text { enterprise }\end{array}$ & $\begin{array}{l}\text { Total revenue in } 2020 \\
\text { (thousand Yuan) }\end{array}$ & $\begin{array}{l}\text { The percentage of } \\
\text { sugar-free } \\
\text { beverage }\end{array}$ & $\begin{array}{l}\text { Revenue (thousand } \\
\text { Yuan) }\end{array}$ \\
\hline $\begin{array}{c}\text { Oriental leaves } \\
\text { Tea Pai }\end{array}$ & \multirow{3}{*}{ Nongfu Spring } & \multirow{3}{*}{22877297} & $13.50 \%$ & 3088435 \\
\hline Scream & & & & \\
\hline $\begin{array}{l}\text { Vitamin water } \\
\text { energy drinks }\end{array}$ & & & $12.20 \%$ & 2791030 \\
\hline Sparkling water & Genki Forest & 2900000 & $70 \%$ & 2030000 \\
\hline $\begin{array}{l}\text { Sugar-free / } \\
\text { Fewer sugar } \\
\text { beverages }\end{array}$ & Coca Cola & 215413049 & $28.20 \%$ & 60746480 \\
\hline
\end{tabular}

Source: Meng Yang [20]

\subsection{Possibility of sustainable development and investment decision}

Through our research, it is reasonable for a venture capitalist to feel optimistic about the People category after evaluating Genki Forest using the POCD framework base on the fact that the founder of Genki Forest, Mr. Tang, can operate the company with novel strategies and has the experience of managing a huge company. On the opportunity side, the stable market development, decentralized market, the development of the modern channel and e-commerce channels, and products that can meet the needs of consumers are the strengths of the company. However, the fierce competition for sugar-free sodas, the impact of negative incidents on Genki Forest's reputation, and the limited strategy are the weaknesses of the company. And then on the context part, although Genki Forest is facing the problems of blocked entry into the sinking market and lack of ability to create popular products continuously in the process of development, people's consumption upgrade, the operation of ecommerce platform and policy support have created a favorable macro environment for the future development of Genki Forest.

Accordingly, from the discussion about Genki Forest by using the POCD framework, it is convinced that Genki Forest is worth further invested for its advantages on sustainable development.

\section{CONCLUSION}

The future development of the Chinese beverage industry is promising. New retail channels will become the main sales channels, and the market is more fragmented, which is suitable for the development of new beverage companies like Genki Forest.

We analyzed the company's founders, the company's opportunities, and the company's environment separately. In terms of PEOPLE and CONTEXT, the future of Genki Forest is promising. However, in terms of OPPORTUNITIES, although the market has good prospects, it faces competition from many head companies in the industry, and its reputation is unstable. Thus, the future development prospects of Genki Forest are very broad.

Our study also verified that the POCD framework is a good analysis method for start-ups to determine from a qualitative perspective whether a start-up can grow rapidly in the future and help venture capital to make investment decisions.

\section{REFERENCES}

[1]https://www1.hkexnews.hk/listedco/listconews/sehk/ 2020/0825/2020082500026_c.pdf

[2] Huang, Xiaoyan, et al. "Daily intake of soft drinks and moderate-to-severe acne vulgaris in Chinese adolescents." The Journal of pediatrics 204 (2019): 256-262.

[3] Dong, Yanhui, et al. "Geographical variation and urban-rural disparity of overweight and obesity in Chinese school-aged children between 2010 and 2014: two successive national cross-sectional surveys." BMJ Open 9.4 (2019): e025559.

[4] Shrapnel, William. "Trends in sugar-sweetened beverages: are public health and the market aligned or in conflict?" Nutrients 7.9 (2015): 8189-8198.

[5] Kharmats, Anna, et al. "The more sugar and calories, the better? Children's perspective on sugarsweetened beverages (262.7)." The FASEB Journal 28 (2014): 262-7.

[6] Jensen, Paul N., et al. "Associations of diet soda and non-caloric artificial sweetener use with markers of glucose and insulin homeostasis and incident diabetes: the Strong Heart Family Study." European journal of clinical nutrition 74.2 (2020): 322-327.

[7] Zhang, Yuhan. "An analysis of the correlation between profitability and liquidity of beverage companies in Chinese market." 2020.

[8] Miloud, Tarek, Arild Aspelund, and Mathieu Cabrol. "Startup valuation by venture capitalists: an 
empirical study." Venture Capital 14.2-3 (2012): 151-174.

[9] Sahlman, William A. "Some Thoughts on Business Plans." Harvard Business School Background Note 897-101, 1996.

[10] Jian Zhang, Bingxin Li. " Research on Chinese consumers' awareness of domestic products: Review and Prospect. Enterprise economy." 2017.10.13529/j.cnki.enterprise.economy.2017.01. 004.

[11] Report.iimedia.cn. Report on the development of Chinese beverage industry segments and typical cases in 2020 .

[12] http://finance.sina.com.cn/chanjing/gsnews/202104-09/doc-ikmxzfmk5916508.shtml

[13] Chengxin Yu, Nan Hai. " Behind the popularity of Genki forest [n]. " China business times, 2020.

[14]http://k.sina.com.cn/article_7542568640_1c19276c 000100rm91.html

[15] Shuguang Shen, Wangfeng Zeng. " Concept, framework and path of healthy China Construction [J]. " Journal of Sun Yat sen University (SOCIAL SCIENCE EDITION), 2020,60 (01): 168-178.

[16] Wei Liang, Dan Shi. " Genki forest, lack of vitality? " Business school, 2020.

[17] Benkang Wang. " Research on the Influence of Experience Marketing on Customer Behavior under the Mode of 'Internet + Convenience Stores' [D]. " Guizhou University, 2017.

[18] Xiaohua Wang. " Research on marketing strategy of beverage channels of Master Kong. " Beijing University of Posts and Telecommunications, 2007.

[19] Meng Yang. " Research on Brand Competitiveness of China's Beverage Industry [D]. " Shaanxi Normal University, 2015.

[20] Sishuo Meng, Jieting Wang. " Food and beverage: 'sugar free' series report: the rise of sugar free beverage. " Dongxing Securities Research Institute, 2021. 